\section{Comment on 'Continuing need for and provision of a service for non-standard implant removal'}

We enjoyed reading the article by Pillai et $a .^{1}$ on the subject of non-standard implant removals. The comments made in response by Bacon and Mahfoud $^{2}$ regarding implants found in the 'wrong' arm led us to consider an audit we are currently undertaking.

We are considering the quality of a Nexplanon ${ }^{\circledR}$ service in a Stockport, Greater Manchester general practice by evaluating a number of procedural objectives, including whether the site of implant is recorded in a patient's notes. We were surprised to conclude that of the 26 procedures looked at, $10 \mathrm{did}$ not state in which arm the implant was located. We believe a common reason for this is that a general practitioner may simply record 'reinserted in original insertion site' without ensuring left or right was ever recorded.

In light of the workload already managed by non-standard removal services, we believe small steps to ensure the basics are recorded could serve to reduce unnecessary referrals and improve the patient experience.

\section{Annaliese Ashman, BSC}

Fourth Year Medical Student, Medical School, University of Manchester, Manchester, and Education Department, University Hospital South Manchester, Manchester, UK; annaliese.ashman@student.manchester.ac.uk

\section{Xuan Gleaves, BSC}

Fourth Year Medical Student, Medical School, University of Manchester, Manchester, and Education Department, University Hospital South Manchester, Manchester, UK;

xuan.gleaves@student.manchester.ac.uk

\section{Harish Thampy, MRCGP}

General Practitioner and Clinical Lecturer, Manchester Medical School, Manchester, UK; harish.thampy@manchester.ac.uk

Competing interests None declared.

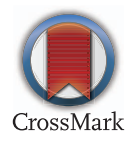

J Fam Plann Reprod Health Care 2015;41:242. doi:10.1136/jprhc-2015-101217

\section{REFERENCES}

1 Pillai M, Gazet AC, Griffiths M. Continuing need for and provision of a service for non-standard implant removal. J Fam Plann Reprod Health Care 2014;40:126-132.

2 Bacon L, Mahfoud H. Comment on 'Continuing need for and provision of a service for non-standard implant removal'. J Fam Plann Reprod Health Care 2014;40:234. 